\title{
Coronary Artery Disease, Microalbuminuria and Lipid Profile in Patients with Non-Insulin Dependent Diabetes Mellitus
}

\author{
Luciana Bahia, Marília B. Gomes, Pedro di Marco da Cruz, Maria de Fátima Gonçalves
}

Rio de Janeiro, RJ - Brazil

\begin{abstract}
Purpose - To determine the frequency of coronary artery disease, microalbuminuria and the relation to lipid profile disorders, blood pressure and clinical and metabolic features.
\end{abstract}

Methods - Fifty-five type 2 diabetic patients $(32$ females, 23 males), aged 59.9 \pm 9 years and with known diabetes duration of $11 \pm 7.3$ years were studied. Coronary artery disease (CAD) was defined as a positive history of myocardial infarction, typical angina, myocardial revascularization or a positive stress testing. Microalbuminuria was defined when two out of three overnight urine samples had a urinary albumin excretion ranging 20 $200 \mu \mathrm{g} / \mathrm{min}$.

Results - CAD was present in 24 patients $(43,6 \%)$. High blood pressure (HBP) present in 32 patients (58.2\%) and was more frequent in CAD group $(p=0.05) \mathrm{HBP}$. Increased the risk of CAD 3.7 times (CI[1.14-12]). Microalbuminuria was present in 25 patients (45.5\%) and tended to associate with higher systolic blood pressure (SBP) $(p=$ $0.06)$, presence of hypertension $(p=0.06)$ and know diabetes duration $(p=0.08)$. In the stepwise multiple logistic regression the systolic blood pressure was the only variable that influenced UAE $\left(r=0.39, r^{2}=0.14, p=0.01\right)$. The hypertensive patients had higher cholesterol levels $(p=0.04)$.

Conclusion - In our sample the frequency of microalbuminuria, hypertension, hypercholesterolemia and CHD was high. Since diabetes is an independent risk factor for cardiovascular disease, the association of others risk factors suggest the need for an intensive therapeutic intervention in primary and in secundary prevention.

Key words: coronary artery disease, microalbuminuria, lipid disorders, diabetes mellitus

Internal Medicine Department, UERJ

Mailing address: Luciana Bahia - Av. Visconde de Albuquerque, 986/102 - 22450-000 - Rio de Janeiro, RJ - Brazil
Diabetes mellitus is an important factor associated with increased cardiovascular morbidity and mortality, due to coronary artery disease (CAD), stroke and peripheral vascular disease. Age adjusted coronary artery disease prevalence in diabetic patients, in the United States, is between 30 and $51 \%$; peripheral vascular disease and stroke prevalences are 9 and $10 \%$, respectively ${ }^{1}$. Recently, a study in Brazil reported a 2.3 greater in-hospital mortality rate in diabetic compared with nondiabetic patients, and the main cause of death was cardiovascular disease ${ }^{2}$.

Today, it is recognized that the presence of microalbuminuria, in addition to being a marker of incipient renal disease in diabetic patients, seems to be also a marker of large vessel disease, and is associated with an increased cardiovascular disease mortality, especially coronary heart disease $^{3-5}$. This increased mortality is due, in part, to a greater prevalence of other risk factors in patients with microalbuminuria, such as lipid disorders, hypertension $(\mathrm{H})$, increased fibrinogen levels and blood rheology changes ${ }^{6,7}$. Recent studies from the World Health Organization demonstrated that the presence of proteinuria-in type 2 diabetic patients (DM2), increased the risk of cardiovascular death 3 to 4 times, independent of other risk factors ${ }^{8}$.

The presence of microalbuminuria possibly reflects the process of generalized vascular damage, affecting simultaneously glomeruli, the retina and the intimal layer of large vessels. This has been demonstrated by studies of markers of endothelial dysfunction and measurements of transcapillary protein leakage $e^{9,10}$.

Some studies suggested a common genetic predisposition for microalbuminuria and the early atherosclerotic process in diabetic patients ${ }^{11}$. Others suggested that glomerular mesangeal cells and arterial smooth muscle cells, being both of mesenchimal origin, would suffer the same changes in response to the different metabolic abnormalities observed in these patients, such as functional extracellular matrix changes with the consequent mesangial and medial proliferation, endothelial dysfunction and protein leakage?

The present study aimed to analyze the association between coronary artery disease, incipient diabetic renal 
disease and lipid and blood pressure parameters in a group of patients with NIDDM regularly treated at the diabetes outpatient facility of the Hospital Universitário Pedro Ernesto.

\section{Methods}

Fifty-five patients with NIDDM were studied (32 women and 23 men, mean age $59.9 \pm 9$ years). Their mean known duration of the disease was $11 \pm 7.3$ years; 7 were smokers and 48 were nonsmokers. They were regularly seen at the diabetes outpatient center. Patients with systemic infections, heart failure and renal failure were excluded (by the presence of hematuria, abnormal sediment or plasma creatinine $>1.5 \mathrm{mg} / \mathrm{dL}$ without proteinuria).

Forty patients used insulin alone or in combination with oral hypoglycemic agents and 15 used only oral antidiabetic drugs. Patients received written instructions to collect three nocturnal urine samples in a maximum six month interval, maintaining the same diet prescribed (55/ $60 \%$ carbohydrates, $25 / 30 \%$ lipids and $15 / 20 \%$ proteins) and activity level in the period. After a 12-hour fast, two venous blood samples were collected, on different days, for the analysis of the following variables: total cholesterol (reference value $(\mathrm{RV})<220 \mathrm{mg} / \mathrm{dL}$ ); triglycerides (RV: 40/ $160 \mathrm{mg} / \mathrm{dL}$ ) and HDL-cholesterol (RV: $35 / 55 \mathrm{mg} / \mathrm{dL})$, glucose (RV: 70/110mg/dL) and glycated hemoglobin (HbA1c) (RV: 4.5/6.2\%). The ratios cholesterol/HDL and LDL/HDL were calculated. LDL was calculated according to Friedwald's formula $^{12}$. Lipid profile was classified according to the American Diabetes Association criteria ${ }^{13}$. Recommended values were: cholesterol $<200 \mathrm{mg} / \mathrm{dL}$, LDL-cholesterol $<130 \mathrm{mg} / \mathrm{dL}$, triglycerides $<200 \mathrm{mg} / \mathrm{dL}$ and HDL-cholesterol $>35 \mathrm{mg} / \mathrm{dL}$. The presented results are the average of the values of the two samples.

Body mass index (BMI) was calculated by dividing the weight $(\mathrm{kg})$ by the square of the height $\left(\mathrm{m}^{2}\right)$. Patients were considered overweight when BMI was $>25 \mathrm{~kg} / \mathrm{m}^{2}$ and obese when BMI was $>30 \mathrm{~kg} / \mathrm{m}^{2}$, following the World Heath Organization criteria ${ }^{14}$.

To evaluate the glycemic control of the patients $\mathrm{HbA} 1 \mathrm{c}$ levels and an index described by Chase (HbA1c/6.2 maximum normal limit) were used ${ }^{15}$. Values $<1.33$ were considered good glycemic control; values 1.33 to 1.5 , average control; and values $>1.5$ were considered poor control.

The measurements were obtained through colorimetric reactions, read on Cobras-Mira Roche equipment. $\mathrm{HbA} 1 \mathrm{c}$ was assessed by high-resolution liquid chromatography, using L-9100 Merck Hitachi equipment. Glucose was determined by the glucose-oxidase method. Albumin urinary excretion (AUE) was determined by radioimmunoassay (DPC-Los Angeles - sensitivity of $0.3 \mu \mathrm{g} / \mathrm{mL}$ ), in nocturnal urine samples, collected in preservative-free vials. Urine samples had to be sterile and were centrifuged and frozen at $-20^{\circ} \mathrm{C}$ (for less than 2 months). Intra-assay and inter-assay variation coefficients were respectively, $2.7 \%$ and $3.5 \%$. Microalbuminuria (micro) was considered present when there were at least 2 of 3 samples with values between $20 \mu \mathrm{g} / \mathrm{min}$ and $200 \mu \mathrm{g} / \mathrm{min}$.

Blood pressure was determined in a supine patient after a 5-minute rest, using standardized mercury sphygmomanometers. Diastolic blood pressure (DP) value was considered when Korotkoff sounds stopped (phase 5). Three measurements were made by the same observer and average values were recorded. Hypertension was defined by values greater than $140 \mathrm{mmHg}$ systolic and/or PD $>90 \mathrm{mmHg}{ }^{16}$ or in patients with a prior diagnosis of hypertension when in the use of antihypertensive medications. The antihypertensive medication was not modified in any patient during urine sample collection.

Forty-three patients underwent a treadmill stress test, using the Bruce protocol, the Quinton treadmill (model Q55) and a computerized real time stress ECG analysis system (Micromed v.2.1). Medications that could interfere with test results were withdrawn $48 \mathrm{hs}$ prior to the test. Clinical hemodynamic and electrocardiographic criteria for effortinduced ischemia were those of the Brazilian Consensus on Ergometry and Rehabilitation ${ }^{17}$.

Statistical analyses were performed using the MannWhitney test for two independent samples with abnormal distribution and Student's $t$ test for the comparison of two independent samples with normal distribution. Chi-square test with the Yates correction was used for categorical variables. For the stepwise logistic regression the abnormally distributed variable underwent a logarithmic transformation. Data are presented as mean \pm standard deviation or median (minimum-maximum) and $\mathrm{p}<0.05$ was considered significant. SPSS (version 6.0) and Epi Info (version 6.0) programs were used. Frequencies are presented along with confidence intervals $(\mathrm{CI})$.

\section{Results}

Patients' clinical characteristics are shown in table I. Of 55 studied patients, 25 [45.5\%, CI (32.9-59.5)] had microalbuminuria and $30[54.5 \%, \mathrm{CI}(40.6-67.8)]$ had normal albuminuria. UAE values were, respectively, 32.2 (17.5108.7) vs 9.6 (1.6-20.6) $\mu \mathrm{g} / \mathrm{min}$. Patients with microalbuminuria had a trend toward higher SBP $(152 \pm 18.7$ vs $142.7 \pm 16.9 \mathrm{mmHg}, \mathrm{p}=0.06)$, for a greater prevalence of hypertension $(72 \%$ vs $46.7 \%, \mathrm{p}=0.06)$ and for greater known duration of the disease $(12.4 \pm 6.6$ vs $9.7 \pm 7.7$ years, $p=0.08)$ than patients with normal albumin excretion. Other studied variables were not statistically different (tab. II). Stepwise regression analysis indicated that the only variable associated with UAE was systolic blood pressure $\left(r=0.39, r^{2}=0.14, p=0.01\right)$.

Hypertension was present in 32 patients [58.2\%, CI (44.1-71)], and 30 patients were on medication (93.7\%). The most used drugs were: angiotensin-converting enzyme inhibitors (14 patients), alone or in association, and calcium channel blockers, isolated or in association (16). Average systolic blood pressure was $146.9 \pm 18.2 \mathrm{mmHg}$ and diastolic blood pressure was $85.1 \pm 9.4 \mathrm{mmHg}$. Despite treatment, 19 $(59.4 \%)$ patients had systolic $\geq 140 \mathrm{mmHg}$ and diastolic 


\begin{tabular}{|lc|}
\hline \multicolumn{2}{|c|}{ Table I - Clinical characteristics of patients with NIDDM } \\
\hline \multicolumn{2}{|l|}{ Variables } \\
\hline Number of patients & 55 \\
Gender (female/male) & $32 / 23$ \\
Age (years) & $59.9 \pm 9$ \\
Duration of diabetes (years) & $11 \pm 7.3$ \\
Race (white/non-white) & $29 / 26$ \\
BMI (kg/m $^{2}$ & $28.7 \pm 5$ \\
Smoking (yes/no) & $7 / 48$ \\
Type of treatment & $40 / 15$ \\
(insulin/OHA) & \\
\hline & \\
NIDDM - non-insulin-dependent diabetes mellitus; BMI - body mass & \\
index; OAH - oral hypoglycemic agents. \\
\hline
\end{tabular}

$>90 \mathrm{mmHg}$. The UAE was significantly higher in hypertensive patients (26.8 [3.7-108.7] vs 14.2 (1.6-42), $\mathrm{p}=0.003)$.

Sixteen $(29.1 \%)$ patients had a history of previous coronary heart disease (myocardial infarction, coronary angioplasty or typical angina), 13 received medication, 10 with calcium channel blockers and 3 with nitrates. Stress tests were obtained from 43 patients. Stress tests in 10 (23.3\%) patients were considered positive; 2 of these patients had a prior history of CAD. The frequency of coronary artery involvement in patients with a prior history of CAD and those with ischemic stress test results was $43.6 \%$ [ $=24 \mathrm{CI}(30.5-57.6)]$. Patients with CAD had a higher frequency of hypertension ( $75 \%$ vs $45.2 \%, \mathrm{p}=0.05$ ), and systolic blood pressure was higher in patients with coronary heart disease $(152.6 \pm 17.6$ vs $1426 \pm 17.7 \mathrm{mmHg}$, $\mathrm{p}=0.03$ ). Hypertension was a risk factor for CAD (relative risk of 3.7 [IC (1.14-12), $\mathrm{p}=0.02]$. There was no association between laboratory data and coronary disease (tab. III).
Mean lipid levels in the total diabetic group were: cholesterol $230.4 \pm 8.2 \mathrm{mg} / \mathrm{dL}$, triglycerides $152.5 \pm 86.2 \mathrm{mg} / \mathrm{dL}$, HDL-cholesterol $53.2 \pm 19.1 \mathrm{mg} / \mathrm{dL}$, LDL $146.7 \pm 46 \mathrm{mg} / \mathrm{dL}$, cholesterol/HDL $4.9 \pm 2$ (females $4.6 \pm 1.9 /$ males $5.2 \pm 2$ ) and LDL/HDL $3.2 \pm 1.6$ (women $2.9 \pm 1.5 /$ men $3.5 \pm 1.7$ ) (tab. II). 38 patients $(69.1 \%$, CI [55-80.5]) had cholesterol $>200 \mathrm{mg} / \mathrm{dL} ; 11$ [20\%, CI (10.8-33.4)] triglycerides $>200 \mathrm{mg} / \mathrm{dL} ; 9 ;[16.4 \%$, CI (8.2-29.3)] had HDL <35mg/dL and 35-[63.6\%,CI(50.3-75.5)] LDL $>130 \mathrm{mg} / \mathrm{dL}$. Hypertensive patients had higher cholesterol levels compared with normotensive patients (240.8 \pm 51.6 vs $215.9 \pm 36.7 \mathrm{mg} / \mathrm{dL}, \mathrm{p}=0.04)$. Women had higher HDLcholesterol levels than men $\operatorname{did}(56.4 \pm 17.4 \mathrm{mg} / \mathrm{dL}$ vs $48.7 \pm$ $20.9 \mathrm{mg} / \mathrm{dL}, \mathrm{p}=0.02$ ).

With regards to glycemic control, 21 (38.2\%) patients had good control, 11 (20\%) had average control and 23 $(41.8 \%)$ had poor control. Patients with cholesterol $>200 \mathrm{mg} /$ $\mathrm{dL}$ had a tendency toward worse metabolic control $(\mathrm{p}=0.05)$. Differences in other parameters were not observed.

Obesity was observed in $29 \%$ of the patients $(n=16)$ and overweight in $52.7 \%(n=19)$, a total of $81.8 \%$ of the sample above ideal weight. These patients had higher cholesterol $(236.7 \pm 49.3$ vs $202.1 \pm 30.5$, $\mathrm{p}=0.02)$, triglycerides $(163.2 \pm 91$ vs $104.2 \pm 30.7,=0.01), \operatorname{LDL}(153.8 \pm 45.7$ vs $114.6 \pm$ $32.4, \mathrm{p}=0.008)$, diastolic blood pressure $(86.3 \pm 9.2 \mathrm{vs}$ $79.8 \pm 9, \mathrm{p}=0.05)$ and lower HDL levels $(50.2 \pm 16.1$ vs $66.6 \pm 26$, $\mathrm{p}=0.05$ ). We observed a greater prevalence of hypertension in overweight patients $(64.4 \%$ vs $30 \%, \mathrm{p}=0.04)$. The presence of CAD was similar in obese and nonobese patients.

\section{Discussion}

The present study is a transverse cohort study of a

\begin{tabular}{|c|c|c|c|}
\hline Varibles & Micro & Normal albumin excretion & $\mathrm{P}$ \\
\hline Number & 25 & 30 & \\
\hline $\mathrm{UAE}(\mu \mathrm{g} / \mathrm{min})$ & $32.2(17.5-108.7)$ & $9.6(1.6-20.6)$ & \\
\hline Age (years) & $59.8 \pm 7.6$ & $59.9 \pm 10.1$ & 087 \\
\hline Duração do diabetes (anos) & $12.4 \pm 6.6$ & $9.7 \pm 7.7$ & 0.08 \\
\hline Smoking (yes/no) & $4 / 21$ & $3 / 27$ & 0.48 \\
\hline $\operatorname{BMI}\left(\mathrm{kg} / \mathrm{m}^{2}\right)$ & $29.8 \pm 5.5$ & $27.8 \pm 4.3$ & 0.17 \\
\hline $\mathrm{SBP}(\mathrm{mmHg})$ & $152 \pm 18.7$ & $142,7 \pm 16,9$ & 0.06 \\
\hline $\mathrm{DBP}(\mathrm{mmHg})$ & $86.1 \pm 9.2$ & $84.3 \pm 9.7$ & 0.53 \\
\hline Hypertension (yes/no) & $18 / 7$ & $14 / 16$ & 0.06 \\
\hline Family history of hypertension (yes/no) & $15 / 10$ & $12 / 18$ & 0.22 \\
\hline CAD (yes/no) & $13 / 12$ & $11 / 19$ & 0.18 \\
\hline Family history of CAD (yes/no) & $7 / 18$ & $13 / 17$ & 0.37 \\
\hline Glucose (mg/dL) & $225 \pm 80.4$ & $208 \pm 72$ & 0.45 \\
\hline Glycosylated hemoglobin $(\%)$ & $9.0 \pm 2.2$ & $8.4 \pm 1.95$ & 0.39 \\
\hline Metabolic control ratio & $1.45 \pm 0.36$ & $1.35 \pm 0.31$ & 0.29 \\
\hline Cholesterol (mg/dL) & $259.9 \pm 59.4$ & $219 \pm 37.4$ & 0.15 \\
\hline HDL (mg/dL) & $54.6 \pm 20.8$ & $52 \pm 17.9$ & 0.75 \\
\hline LDLc (mg/dL) & $136.7 \pm 35.8$ & $155 \pm 52$ & 0.14 \\
\hline Triglycerides(mg/dl) & $138.4 \pm 67.7$ & $164.2 \pm 98.7$ & 0.26 \\
\hline LDLc/HDL ratio & $2.8 \pm 1.1$ & $3.4 \pm 1.8$ & 0.41 \\
\hline Cholesterol/HDL ratio & $4.4 \pm 1.4$ & $5.2 \pm 2.3$ & 0.46 \\
\hline
\end{tabular}




\begin{tabular}{|c|c|c|c|}
\hline \multicolumn{4}{|c|}{ Table III - Clinical and laboratorial variables in patients with or without coronary artery disease } \\
\hline Variables & Positive coronary artery disease & Negative coronary artery disease & $\mathrm{P}$ \\
\hline Number & 24 & 31 & \\
\hline Gender (female/male) & $11 / 13$ & $20 / 11$ & 0.16 \\
\hline Age (years) & $61.2 \pm 10.2$ & $58.7 \pm 7.8$ & 0.1 \\
\hline Diabetes duration (years) & $12.5 \pm 7.3$ & $9.72 \pm 7.2$ & 0.16 \\
\hline Glycated hemoglobin (\%) & $8.6 \pm 1.6$ & $8.7 \pm 2.4$ & 0.93 \\
\hline Metabolic control index & $1.4 \pm 0.25$ & $1.4 \pm 0.4$ & 0.93 \\
\hline Cholesterol & $230 \pm 44$ & $230.7 \pm 51.8$ & 0.98 \\
\hline Triglycerides & $163.4 \pm 103.2$ & $144 \pm 70.9$ & 0.52 \\
\hline HDL (mg/dL) & $50 \pm 17.8$ & $55.6 \pm 20$ & 0.18 \\
\hline LDLc (mg/dL) & $147.3 \pm 40.2$ & $146.3 \pm 50.6$ & 0.62 \\
\hline UAE $(\mu \mathrm{g} / \mathrm{min})$ & $18.6(3.7-108.7)$ & $14.1(1.6-85)$ & 0.12 \\
\hline SBP & $152.6 \pm 17.6$ & $142.6 \pm 17.7$ & 0.03 \\
\hline DBP & $86.7 \pm 9.7$ & $83.9 \pm 9.2$ & 0.26 \\
\hline $\mathrm{HBP}-\mathrm{n}(\%)$ & $18(75)$ & $14(45.2)$ & 0.05 \\
\hline Obesity - n (\%) & $20(83.3)$ & $25(80.6 \%)$ & 0.80 \\
\hline
\end{tabular}

population with NIDDM treated at a University Hospital, a reference center for the State of Rio de Janeiro.

Transverse cohort and longitudinal studies have demonstrated that microalbuminuria is a predictor of large vessel disease ${ }^{3-5}$. Its prevalence varies in patients with diabetes from 7.6 to $42 \%{ }^{18-20}$. Many factors contribute to this: race, diabetes duration, microalbuminuria criteria and size and design of the studies. Similar to the present study, several other reports in the literature associate microalbuminuria with systolic blood pressure ${ }^{7,19,21}$. The association with diastolic blood pressure is less evident. It is important to emphasize that the association is also described in nondiabetic populations, suggesting the presence of a relation with the high insulin resistance syndrome ${ }^{22}$. The association with the duration of diabetes is also controversial, with studies showing microalbuminuria in recently diagnosed patients ${ }^{23}$. This could be explained by the fact that in most patients with NIDDM the actual duration of the diabetes is unclear. The frequency of microalbuminuria in our group was $45.5 \%$, with a tendency for increased systolic blood pressure, duration of the diabetes and hypertension In the stepwise multiple regression analysis, systolic blood pressure was the only variable that significantly influenced the rate of UAE. We did not observe a relation between $\mathrm{HbA} 1 \mathrm{c}$ and microalbuminuria, sometimes reported ${ }^{24,25}$ or not $^{26,27}$ in the literature. Possibly, transverse cohort studies, such as ours, are less likely to reveal the influence of glycemic control on the development of microalbuminuria.

Confirming other reports in the literature, the frequency of hypertension in our sample was $58.2 \%$, being more common in patients with microalbuminuria ${ }^{19,22,24}$ and overweight ${ }^{28}$. We observed that $19(59.4 \%)$ treated patients; still had blood pressure levels over $140 / 90 \mathrm{mmHg}$, in spite of the fact that $43 \%$ of them had already been using two or more antihypertensive drugs, demonstrating inadequate pressoric control, according to the levels suggested by the American Diabetes Association and the Joint National
Committee ${ }^{29}$. This information is relevant because, in a recent multicenter study, diabetic patients who maintained diastolic blood pressure $<80 \mathrm{mmHg}$ had lower mortality and cardiovascular events ${ }^{30}$. The high prevalence of hypertension among patients with normal UAE suggests, possibly, the presence of essential hypertension not related to incipient diabetic or clinical renal disease. This is not observed on type 1 diabetic patients who present hypertension in advanced phases or clinical renal disease ${ }^{31}$.

The presence of diabetes increases the risk of CAD two-to four-fold in comparison with the risk in the general population. There are, however, large differences in the prevalence of risk for CAD among different countries. This was evaluated in a multicenter study on vascular disease in diabetic patients sponsored by the World Health Organization, which followed 4,714 patients for 10 years studying causes of death and risk factors ${ }^{8}$. There was a large variation in the prevalence of CAD and, despite that these patients had a greater frequency of hypertension and lipid disorders, the main independent risk factor for coronary disease was the presence of proteinuria. Other transverse population studies in diabetic patients demonstrated that cardiovascular risk depends on race. Thus, American Pima Indians and Japanese have a lower risk than the American white population ${ }^{32}$, suggesting genetic and environmental differences in the prevalence of CAD. The classical results reported in the Framingham study suggest that the presence of risk factors adversely affects the development of macrovascular disease both in nondiabetic and NIDDM patients ${ }^{33}$. In our group, CAD frequency was $43.6 \%$, similar to the 40 to $50 \%{ }^{24,34}$ reported in the literature. We observed that there was a greater prevalence of hypertension in these patients, with a risk ratio of 3.7 for coronary disease, confirming prior reports in the literature. This is important because cardiac mortality among diabetic patients increases threefold when there is associated hypertension ${ }^{24}$. Several studies demonstrated the association of CAD with microalbuminuria ${ }^{3,5,7,10,11}$, which was not observed in our sample. 
Although we cannot exclude a type 2 error, due to the size of the sample, other reports in the literature stress that CAD is associated mainly with macroalbuminuria and not microalbuminuria ${ }^{24-26,33,35}$. Possibly, this divergence with the literature, excluding data inherent to the studied population, is due to different methods and criteria for coronary disease and microalbuminuria diagnoses.

In the lipid analysis we did not use the criteria recommended by the Brazilian Consensus on Lipid Disorders ${ }^{36}$, since those criteria were not based on the Brazilian diabetic population. In our group the prevalence of hypertriglyceridemia and low HDL levels was similar to that reported in the literature ${ }^{37,38}$. Frequency of hypertriglyceridemia seems larger in recently diagnosed patients and during phases of acute decompensation. We observed a high prevalence of hypercholesterolemia and increased LDL levels. Some factors can explain this finding, such as increased age of the study population (some studies demonstrated that LDL levels increase with age after 50/55 years in men and 60/65 in women $^{14,39}$, increased consumption of saturated fat and cholesterol in the diet, which was not assessed in our study, and the presence of genetic lipid disorders. If we adopt the recommendation of $\mathrm{LDL}<100 \mathrm{mg} / \mathrm{dL}$, as proposed for patients with macrovascular disease, $90.9 \%$ of our sample would be characterized as having dyslipidemia $(n=50)$, which would call for an intense secondary prevention effort. Patients with hypercholesterolemia had a tendency for worse glycemic control. A similar finding was not observed in patients with hypertriglyceridemia possibly because only $11(20 \%)$ patients had this lipid disorder. We believe that the influence of glycemic control on lipids should be analyzed in large prospective studies, especially with the allocation of patients to intensive and conventional treatment groups. A study observing this design did not demonstrate influence of the glycemic control on different lipid parameters after a 30-month follow-up of patients with $\mathrm{NIDDM}^{40}$. Data from a longitudinal study in the United Kingdom(UKPDS) have provided information with respect to the relation between these events. However, it is important to emphasize that glycemic control can influence specific phases of the metabolism of lipids, such as the reverse transport of cholesterol. Recently, it was demonstrated that the glycation of HDL, especially the subfraction $\mathrm{HDL}_{3}$, favors a faster and more efficient transfer of cholesterol from this fraction to apoprotein B-containing lipoproteins ${ }^{41}$. We did not observe an association between lipid disorders and CAD, as described in studies with diabetic and nondiabetic patients ${ }^{39,42,43}$. Possibly isolated lipid determinations are not enough to detect the association of these events. This finding was observed in studies in populations from Europe and Brazilian private practices ${ }^{39}$, which included diabetic patients and used diagnostic criteria for CAD and lipid disorders similar to those of our study. We know, today, that there are several other factors, genetic and nongenetic, that can influence the basic process of the disease, i.e. atherosclerosis, such as the apolipoprotein B and paraoxanases genetic polymorphism ${ }^{44}$, the presence of lipoprotein (a) ${ }^{37}$, increased oxidized LDL and its affinity to proteoglycans of the intimal layer of the vessel wall ${ }^{45}$. These factors could trigger different responses in the endothelium that would favor the development of atherosclerotic plaque.

We conclude that patients with NIDDM, treated in a tertiary care center, had a high prevalence of incipient renal disease, hypertension, hypercholesterolemia and coronary disease. Hypertension was associated with CAD and systolic blood pressure with microalbuminuria. However, these factors could only be considered risk factors in a longitudinal study. Since diabetes is an independent cardiovascular risk factor, the frequent aggregation of other risk factors increases considerably the morbidity and mortality of diabetic patients, emphasizing the importance of the adoption of aggressive therapeutic measures toward glycemic, lipid and pressure control during primary and secondary prevention.

\section{Acknowledgements}

To Drs. Roberto Pozzan, Walmir Rathier, José Ricardo Poubel, Helena Gazolla and Trude Dimetz.

\section{References}

1. Eastman RC, Kenn H. The impact of cardiovascular disease on people with diabetes: the potencial for prevention. Lancet 1997; 350(suppl I): 29-32.

2. Cunha EP, Marques EP, Gomes MB. Perfil de pacientes diabéticos internados em Hospital Universitário no Rio de Janeiro. Arq Bras Endocrinol Metab 1992; 39 : 111-15.

3. Jarret RJ, Viberti GC, Argyropoulos A, et al. Microalbuminuria predicts mortality in non-insulin-dependent diabetes. Diabetic Med 1984; 1: 17-19.

4. Mogensen CE. Microalbuminuria predicts clinical proteinuria and early mortality in maturity-onset diabetes. N Eng J Med 1984; 310: 356-60.

5. Neil A, Hawkins M, Potok M, Thorogood M, Cohen D, Mann J. A prospective population-based study of microalbuminuria as a predictor of mortality in NIDDM. Diabetes Care 1993; 7: 996-1003.

6. Niskanen L, Uusitupa M, Sarlund H, et al. Microalbuminuria predicts the development of serum lipoprotein abnormalities favouring atherogenesis in newly diagnosed type 2 diabetic patients. Diabetologia 1990; 33: 237-43.

7. Haffner SM, Morales PA, Gruber MK, Hazuda HP, Stern MP. Cardiovascular risk factors in non-insulin-dependent diabetic subjects with microalbuminuria. Arterioscler Thromb 1993; 13: 205-10.

8. Stephenson JM, Kenny S, Stevens LK, Fuller JH, Lee E, and the WHO Multinational Study Group. Proteinuria and Mortality in Diabetes: the WHO Multinational Study of Vascular Disease in Diabetes. Diabetic Med 1995; 12 : 149-55.

9. Deckert T, Feldt-Rasmussen B, Borsch-Johnsenk K, et al. Albuminuria reflects widespread vascular damage. The steno hypothesis. Diabetologia 1989; 32: 219-26.

10. Stehouwer CDA, Nauta JJ, Zeldenrust GC, et al. Urinary albumin excretion, 
cardiovascular disease and endothelial dysfunction in non-insulin-dependent diabetes mellitus. Lancet 1992; 340: 319-23.

11. Yudkin JS. Microalbuminuria: a genetic link between diabetes and cardiovascular disease? Ann Med, 1992; 24: 517-22.

12. Friedwald WT, Levy RJ, Frederickson DS. Estimation of the concentration of low density lipoprotein cholesterol in plasma without use of the preparative ultracentrifuge. Clin Chem 1972; 18: 499-502.

13. Detection and Management of Lipid Disorders in Diabetes. Consensus of American Diabetes Association. Diabetes Care, 1996.

14. World Health Organization: Measuring Obesity: Classification and Description of Anthropometric Data, Copenhagen, WHO, 1989.

15. Chase HP, Jackson WE, Hoops S, et al. Glucose control and the renal and retinal complications of insulin-dependent diabetes. JAMA 1989; 261: 1150-60.

16. Joint National Committee on Detection, Evaluation and Treatment of High Blood Pressure. Arch Int Med 1993; 153: 154-83.

17. Consenso Nacional de Ergometria. Arq Bras Cardiol 1995; 65: 190-211.

18. Gatling W, Knight C, Mullee MA, Hill RD. Microalbuminuria in diabetes: a population study of the prevalence and an assessment of three screening tests. Diabetic Med 1988; 5: 343-7.

19. Olivarius N, Andreasen AH, Keiding N, Mogensen CE. Epidemiology of renal involvement in newly-diagnosed middle-aged and elderly-diagnosed patients:cross- sectional data from the population-based study "Diabetes care in general practice", Denmark. Diabetologia 1993; 36: 1007-16.

20. Schimtd A, Vaeth M. Microalbuminuria: a major risk factor in non-insulin dependet diabetes: a 10 year follow-up study of 503 patients. Diabetic Med 1987; 5: 126-34.

21. Patrick AW, Williams Z. The natural history and associations of microalbuminuria in type 2 diabetes during the first year after diagnosis. Diabetic Med 1990; 7: 902-8.

22. Mykkänen L,Zaccaro DJ, Wagenknecht LE, Robbins DC, Gabriel M, Haffner SM Microalbuminuria is associated with insulin resistance in nondiabetic subjects. The Insulin Resistance Atherosclerosis Study. Diabetes 1998; 47: 793-800.

23. Uusitupa M, Siitonen O, Penttil AL, et al. Proteinuria in newly diagnosed type 2 diabetic patients. Diabetes Care 1987; 10: 191-4.

24. Gall MA, Rossing P, Skott P, et al. Prevalence of micro and macroalbuminuria, arterial hypertension, retinopathy and large vessel disease in European type 2 (non-insulin-dependent) diabetic patients. Diabetologia 1991; 34: 655-61

25. Savage S, Estacio RO, Jeffers B, Schrier RW. Urinary albumin excretion as predictor of diabetic ratinopathy, neuropathy, and cardiovascular disease in NIDDM. Diabetes Care 1996; 19: 1243-8.

26. Lee KU, Park JY, Kim SW, et al. Prevalence and associated features of albuminuria in koreans with NIDDM. Diabetes Care 1995; 18: 793-5

27. Torffvit $\mathrm{O}$, Agardh E, Agardh CD. Albuminuria and associated medical risk factors: a cross-section study in 451 type II (noninsulin-dependent) diabetic patients. Part 2. J Diabetic Compl 1991; 5: 29-34.

28. Burto BT, Foster WR. Health implications of obesity:an NIH consensus development conference. J Am Diet Assoc 1985; 85: 1117-21.
29. The Fifth Report of the Joint National Committee on Detection, Evaluation, and Treatment of High Blood Pressure (JNC V). Arch Intern Med 1993; 153: 154-83.

30. Hansson L, Zanchetti A, Carruthers SG, et al. Effects of intensive blood-pressure lowering and low-dose aspirin in patients with hypertension: principal results of the Hypertension Optimal Treatment (HOT) randomised trial. Lancet 1998 351: 1755-62.

31. Gomes MB, Lucchetti MR, Gazzola H, Dimetz T, Lobão VI, Sturm JA. Perfil lipídico, microalbuminúria e pressão arterial sistêmica em pacientes com diabetes insulino-dependente. Arq Bras cardiol 1997; 68: 85-9.

32. Nelson RG, Sievers ML, Knowler WC, et at. Low incidence of fatal coronary heart disease in Pima Indians despite high prevalence of non-insulin-dependent diabetes. Circulation 1990; 81: 987-95.

33. Kannel WB. Lipids, diabetes and coronary heart disease: insights from the Framingham Study. Am Heart J 1985; 110: 1100-7.

34. Uusitupa M. Siitonen O, Aro A. Prevalence of coronary heart disease, left ventricular failure and hypertension in middle-age newly diagnosed type 2 diabetic patients. Diabetologia 1985; 28: 22-7.

35. Gall MA, KB-Johnsen, Hougaard P, Nielsen FS, Parving H-H. Albuminuria and poor glycemic control predict mortality in NIDDM. Diabetes 1995; 44: 1303-9.

36. Groop L, Forlblon C, Lehtovirta M, et al. Insulin resistance, hypertension and microalbuminuria in patients with type 2 diabetes mellitus. Diabetologia 1993 36: 642-7.

37. Consenso Brasileiro sobre Dislipidemia: detecção-avaliação-tratamento. Arq Bras Cardiol 1996; 67: 109-28.

38. Taskinen MR. Diabetic dyslipidemia in NIDDM. International Diabetes Monitor 1996; 8: 1-7.

39. Stern MP, Mitchell BD, Haffner SM, Hazuda HP. Does glycemic control of type II diabetes suffice to control diabetic dyslipidemia? Diabetes Care 1992; 15: 638-44.

40. Luz PL, Carvalho MEA, Cardoso RH, Gallocci SDB, Pileggi F. Incidência de dislipidemia e sua relação com doença arterial coronária em populações brasileiras. Arq Bras Cardiol 1990; 54: 257-64.

41. Abraira C, Colwell JA, Nuttall SQ, et al. Veterans Affairs Cooperative Study on glycemic control and complications in type 2 diabetes (VACSDM): Results of the feasibility trial. Diabetes Care 1995; 18: 1113-23.

42. Passarelli M, Catonozi S, Nakandakare ER, Morton RE, Shimabukuro AFM Quintão ECR. Plasma lipoproteins from patients with poorly controlled diabetes mellitus and "in vivo" glycation of lipoproteins enhance the transfer rate of cholesteryl ester from HDL to apo-B-containing lipoproteins. Diabetologia 1997; 40: 1085-93.

43. Koistinen MJ, Huikuri HV, Korhonen UR, et al. Asymptomatic coronary heart disease in diabetes: realtion to comum risk factors, lipoproteins, apoproteins and apoE polymoephism. Acta Diabetol 1994; 31: 210-14.

44. Mattock MB, Keen H, Viberti GC, et al. Coronary heart disease and urinary albumin excretion rate in type 2 (non-insulin-dependent) diabetic patients. Diabetologia 1988; 31: 82-7.

45. Mackness S, Mackness MI, Arrol S, et al. Serum paraoxanase (PONI) 55 and 192 polymorphism and paraoxonase activity and concentration in non-insulin dependent diabetes mellitus. Atherosclerosis 1998; 139: 341-9. 